\title{
The strategy of information dissemination in a specific field
}

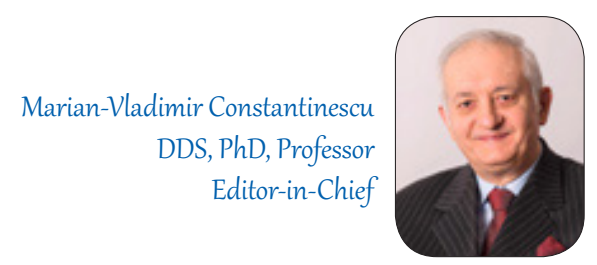

Dear readers,

As a member of the editorial board of our Journal, we have been trying, together with the other two Editors-in-Chief, Professor Jean-François Roulet (University of Florida) and Professor Rolf Ewers (Medical University of Vienna), to promote the Stomatology Edu Journal as much and as well as possible within the international academic community via all communication channels.

There has been no scientific event which 1 attended without my introducing our Journal and also asking for original manuscripts to be published by our young Journal.

If we analyze the calendar of editorial events of this year which is coming to an end, there are significant events that 1 am very pleased to share with you.

Due to the spirit of openness to make full use of dissemination of scientific information that promotes high quality research, and the extraordinary generosity of Professor Michael Glick, Editor of the American Dental Association Journal, JADA, Mr. Michael Springer, Publisher, JADA, Mr. Nawin Gupta, Director of Business Operations, ADA and Mrs Stefanie K. Jewell-Thomas, Elsevier, our readers are now the recipients of 1 article with CE Program FAQs for every one of our issues. This comes as an additional incentive for our readers. For this year's last issue of the Stomatology Edu Journal, the American Dental Association was so generous to provide our readers with access to Baking Soda Dentifrices and Oral Health articles; the five articles were published as a supplement to JADA's November 2017 issue (Volume 148, Number 11); readers may participate in the associated CE online activity (free-ofcharge) to earn $2 \mathrm{CE}$ credits.

Since the online edition of the Stomatology Edu Journal's first issue, in March this year there were over 94,000 readers, out of which over 23,000 in the US; now in early December, the fourth issue has more than 130,000 readers out of which over 45,000 readers in the US who visited more than 1,150,00o pages.'

This year as well, the visibility of the print and online editions of the Stomatology Edu Journal has been enhanced by Crossref's assignment of a unique alphanumeric string, the Digital Object Identifier (DOI). This DOI identification is assigned to all published articles starting with the first issue.

It was by using the DOI identifier that Professor David C. Watts, PhD, FADM, Professor of Biomaterials at the University of Manchester, Manchester, United Kindom, Editor-in-Chief of Dental Materials, published by Elsevier for The Academy of Dental Materials, found the Editorial written by Professor Roulet for the 2nd issue of the Stomatology Edu Journal. Professor David C. Watts requested the full reproduction of the editorial written by Professor Roulet in Dental Materials. Academician Alexandru Surdu, Vice President of the Romanian Academy, in his capacity of responsible for publications, agreed on behalf of the Permanent Bureau of the Romanian Academy, on the condition 
that a specification is made that the article was originally published by the Stomatology Edu Journal. Thus, a top article entitled "A consensus-based approach to evidence-based clinical practice" published by a young journal made internationally available by its publication in Dental Materials. This is the first dental journal rated with Impact Factor (IF): 4,070, 5-Year Impact Factor: 5,155, SClmago Journal Rank Indicator (SJR): 2,149 and H Index 114. ${ }^{3}$ Stomatology Edu Journal, the publication that has been published online and in print since 2014, is recognized now by a number of databases, such as the National Library of Medicine (NLM), Crossref, SHERPA / RoMEO, Google Scholar, InfoBase Index (IBI Factor 2015: 2,76) and Academia edu. Currently, our journal is being evaluated by the Scientific Index Services (SIS) and the Directory of Open Access Journals (DOAJ) and in early 2018 it will be subject to admission to Medline, PubMed Central (PMC) and Emerging Sources Citation Index (ESCI).

For its vigorous entry into the value chain of quoted publications, as of this year's issue number 3, all references to articles that will be published online include DOI and active links from PubMed, Google Scholar and Scopus. This is an ample retrospective integrating process that will include all the 95 articles published so far. A laborious and noble activity that must be granted full participation by the editorial team.

Last but not least, we must acclaim Professor Adrian Bejan, J.A. Jones Professor of Mechanical Engineering at Duke University, North Carolina, USA, Honorary Member of the Romanian Academy, Department of Technical Sciences, Deputy Editor-in-Chief of the Stomatology Edu Journal, who has been honored by the award of the Medal "Benjamin Franklin" in Mechanical Engineering for 2018. The Franklin Institute, since its foundation in 1824, has publicly acknowledged the remarkable achievements in science and technology of Nikola Tesla, Marie and Pierre Curie, Thomas Edison, Albert Einstein, Stephen Hawking,Jane Goodall, Bill Gates, and many others. 118 of its medal recipients are Nobel Price laureats. Professor Bejan has distinguished himself by his "interdisciplinary contributions to thermodynamics and heat transfer through convection, as well as to his important contribution to constructal theory, which anticipates natural design and its evolution in engineering, science and social systems."4

At the very end of the year, 1 warmly invite the Stomatology Edu Journal Editorial Board to thoroughly analyze the work done for Stomatology Edu Journal as compared to their council colleagues. This is an invitation 1 am launching to improve the activity as service for the over 130,ooo readers of the Stomatology Edu Journal, so that they could enhance the patents' quality of life by the treatments administered for better health.

I would like to take this opportunity, on behalf of the whole editorial board, to wish you and your loved ones a blessed Christmas, a Happy New Year, and a home full of peace, health, well-being and joy.

Happy New Year!

M-V Constantinescu

Editor-in-Chief

References

1. https://server4.megahost.net:2083/cpsess4450216024/awstats.pl?month= all\&year=2017\&output $=$ main\&config $=$ stomaeduj.com\&lang=en\&ss $=\& f r \quad 3$. amename $=$ index.

2. Roulet JF. Consensus - an alternative way to generate evidence

2017:4(2):82-83. doi: 10.25241/stomaeduj.2017.4(2).edit.1

RouletJF. A consensus-based approach to evidence-based clinical practice. Dent Mater. 2017:33(10):1067-1068. doi: http://dx.doi.org/10.1016/j. dental.2017.08.184 for practitioners to use (or evidence based revisited). Stoma Edu J. 4. https://www.fi.edu/franklin-institute-awards. 